\title{
Low Carbon Concrete Prepared with Scattering-Filling Coarse Aggregate Process
}

\author{
Weiguo Shen ${ }^{1), 2), *}$, Chuan Zhang ${ }^{2)}$, Xinling $\mathrm{Li}^{2)}$, Hua Shi ${ }^{2)}$, Guiming Wang ${ }^{2)}$, and Xiaowu Tian ${ }^{2)}$
}

(Received December 6, 2013, Accepted May 7, 2014, Published online June 11, 2014)

\begin{abstract}
The volume fraction of the coarse aggregate in the conventional plastic concrete is controlled relatively low to ensure a required workability. In this paper, a new type of coarse aggregate interlocking concrete with strength ranging from C30 to C80 was prepared with scattering-filling aggregate process. The strength of concrete prepared with this method increases obviously whereas the shrinkage decreases significantly, the cement dosage in the concrete decreased $20 \%$ at the same time. The microhardness of the ITZ between the cement paste and scattering-filling aggregate is higher than that of the original aggregate, the ITZ become narrower and tighter also. The interlocking and more even distribution of the coarse aggregate and the water absorption of the addition of extra amount of coarse aggregates contribute to the strength and performance improvement of the concrete prepared with scattering-filling aggregate process.
\end{abstract}

Keywords: coarse aggregates, scattering-filling aggregate process, aggregate interlocking concrete, strength, shrinkage, interfacial transition zone.

\section{Introduction}

Concrete is arguably the most widely used manufactured materials in the world, the production processes of concrete result in tremendous environmental impact, cement is the most remarkable ingredient in the concrete which has the largest resource consumption, energy intensity, green house gases and acid rain gases emission (Mehta 1999; Van Oss and Padovani 2003; Mizuguchi 1998), the manufacture of Portland cement (PC) is responsible for up to $10 \%$ of anthropogenic $\mathrm{CO}_{2}$ emissions worldwide, to prepare qualified concrete with low cement content is a very effective approach to reduce the total environment impact of the concrete even the human activity $\mathrm{CO}_{2}$ emission. The concrete is a three phased material: aggregate particles, interfacial transitional zone (ITZ) and cement paste matrix (Nilsen and Monteiro 1993), the coarse aggregate is the strength framework of the plain concrete and it is the structure unit with highest strength, volume stability, durability and lowest cost in the most concrete (Özturan and

\footnotetext{
${ }^{1)}$ State Key Laboratory of Silicate Materials for Architecture, Wuhan University of Technology, Wuhan 430070, China.

*Corresponding Author; E-mail: shenwg@whut.edu.cn

${ }^{2)}$ Material Science and Engineering School, Wuhan

University of Technology, Wuhan 430070, China.

Copyright $($ The Author(s) 2014. This article is published with open access at Springerlink.com
}

Çeçen 1997; Beshr and Almusallam 2003). As a composition material, the concrete's hydration heat, shrinkage, permeability and creep will decrease, whereas the strength, elasticity modulus and anti-cracking will increase with the increase of coarse aggregate content (Stock et al. 1979; Counto 1964; Hirsch 1962). The conventional plastic or fluidal concrete is prepared by mixing the binders (cement and mineral admixture), fine aggregate, coarse aggregate and water together then placing and vibrating the mixture to fabricate a consolidated matrix (illustrated in Fig. 1a). In order to keep the fresh mixture a reasonable flowability and avoid gravity segregation, the aggregate content in the conventional concrete (especially those high strength high performance concrete) keeps relatively low (Alexanderson 1971), the total aggregate volume fraction in high performance concrete is around $65 \%$ (Mehta and Monteiro 1993), and the coarse aggregate volume ratio is around $40 \%$, so the aggregates can't act fully as the matrix structure of the concrete, the high volume fraction of cement paste increases the permeability, creep and drying shrinkage of the concrete (Mehta and Monteiro 1993). The first author invented a new concrete placing process named scattering-filling aggregate method: adding 10-30\% (by the volume of the finished concrete) of coarse aggregate while the concrete is being poured, paved or placed, then vibrating the matrix to form a consolidated concrete (Shen et al. 2010a, b; Shen et al. 2008) (illustrated in Fig. 1). This concrete content 10-30\% less cement than the conventional concrete so it is a typical low carbon concrete, in this paper the strength, shrinkage of this new kind of concrete with strength degree ranging from $\mathrm{C} 30$ to $\mathrm{C} 80$ is studied, the mechanism of concrete strength increase is discussed. 


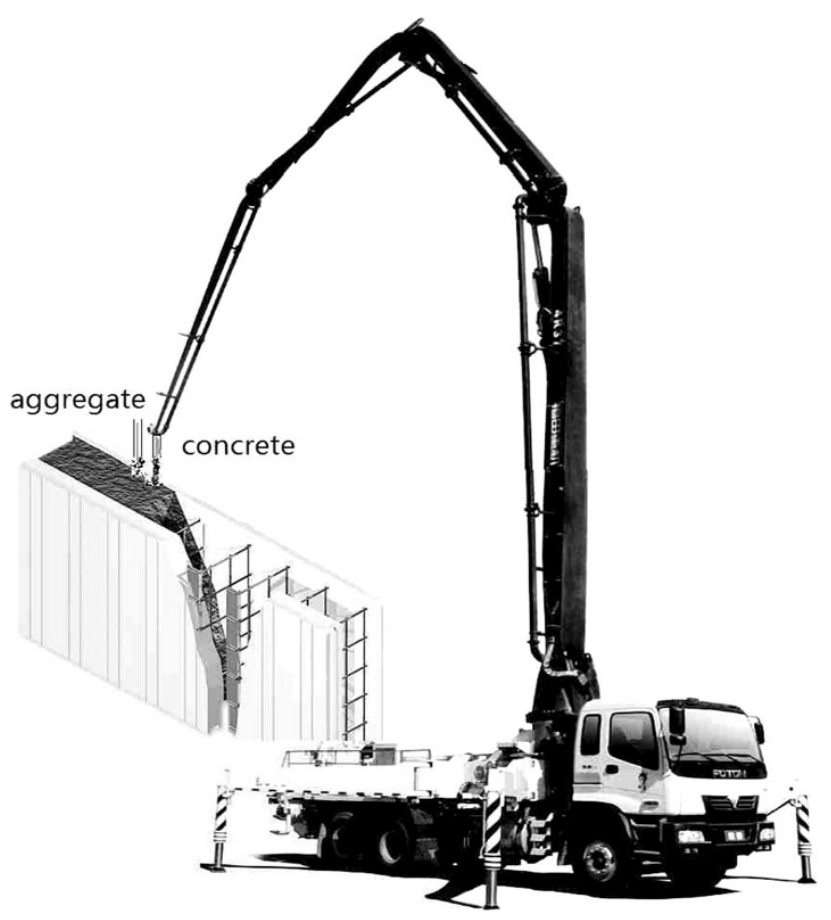

Fig. 1 Schematic diagram of the scattering-filling concrete placing process.

\section{Experiments}

\subsection{Materials}

The 32.5 grade Portland slag cement (P.S 32.5), 42.5 grade and 52.5 grade Portland Conventional cement (P.O 42.5 and P.O 52.5) supplied by Jingmen Sanxia Cement Ltd were used in this investigation. The properties of those cements are shown in Table 1. The chemical compositions of them are presented in Table 2.

The fly ash supplied by Xiangfan Thermoelectric Plant was used in this investigation. The $0.045 \mathrm{~mm}$ screen residue of the fly ash was $4.7 \%$. The chemical compositions of those materials are presented in Table 2.

Four kinds of coarse aggregates were used in this investigation, they were $10-30 \mathrm{~mm}$ crushed limestone (LS-1), 10-30 mm gravel (GS-1), 20-40 mm crushed limestone (LS-2) and 20-40 mm diabase crushed stone (DS-1). Two kinds of fine aggregates were used in this investigation, they were yellow sand (YS) with a fineness modulus of 2.74 and dark sand (DS) with a fineness modulus of 2.19. A polynaphthalene sulphonate superplasticizer with a trade name as FDN was used in this investigation.

\subsection{Specimens}

The aggregate interlocking concrete test cubes were prepared by a simulating scattering-filling aggregate process in the laboratory. First a conventional concrete mixture was prepared with the general process. One layer of this mixture was scattered in the bottom of the mould, following by a layer of coarse aggregates, a further layer of mixture and another layer of coarse aggregates. Generally with three layers of aggregates scattered in each $150 \times 150 \times 150 \mathrm{~mm}^{3}$ mould, then vibrated the moulds for $40-75 \mathrm{~s}$ till the concretes were consolidated.

The strength of the concrete cubes prepared with scattering-filling aggregate process invented by the author are investigated comparing with those normal concretes prepared with conventional process, in order to get reliable results, the specimens were prepared with different cements, aggregates and mix proportions, the strength ranges from $\mathrm{C} 30$ to $\mathrm{C} 80$. The conventional concrete mixture proportions and the sorts of the adding aggregate were listed in Table 3.

\subsection{Items of Investigation}

The compressive strength of the concrete: At the age of 7 , 28 days, concrete specimens were tested for compressive strength respectively, three $150 \times 150 \times 150 \mathrm{~mm}^{3}$ were tested for each date point.

Shrinkage specimens of the three prisms with a size of $100 \times 100 \times 515 \mathrm{~mm}^{3}$ were tested for each date point after being cured in a chamber with $60 \%$ relative humidity. Three specimens were tested for each date point.

The micro-hardness was measured by a HXS-1000 Vickers Micro-hardness Meter Produced in Shanghai Shangguang microscopy Lt.D, which is an average of 3 points for a data points (Beste and Jacobson 2003). In the experiment, the testing point distributed across the aggregate and cement paste interfacial transition zone to measure the hardness distribution of ITZ of different concrete sample.

\section{Results and Discussion}

\subsection{The Effect of the Adding Aggregate Volume on the Concrete Strength}

The conventional concretes with strength grade varying from $\mathrm{C} 30$ to $\mathrm{C} 80$ are prepared with various kinds of aggregates, cement, mineral admixture and mixing proportions, the aggregate interlocking concretes are prepared with

Table 1 The physics technique properties of cements.

\begin{tabular}{c|c|c|c}
\hline Cement sort & P.S 32.5 & P.O 42.5 & 25.7 \\
\hline \hline Normal consistency \% & 26.0 & 165 & 29.5 \\
\hline Initial setting time Min & 173 & 257 & 110 \\
\hline Final setting time Min & 296 & $6.7 / 34.5$ & $5.2 / 26.5$ \\
\hline 3d strength (flexural/compressive) \\
Mpa
\end{tabular}


Table 2 The chemical compositions of raw materials.

\begin{tabular}{c|c|c|c|c|c|c}
\hline Compositions (\%) & P.S 32.5 & P.O 42.5 & P.O 52.5 & Fly ash & GGBS & Silica fume \\
\hline \hline Loss & 1.95 & 1.81 & 2.58 & 1.57 & 1.8 & 0.92 \\
\hline $\mathrm{CaO}$ & 58.2 & 60.89 & 60.68 & 4.51 & 35.36 & 0.45 \\
\hline $\mathrm{SiO}_{2}$ & 21.91 & 22.64 & 21.96 & 56.7 & 33.14 & 96.23 \\
\hline $\mathrm{Al}_{2} \mathrm{O}_{3}$ & 7.62 & 5.32 & 5.86 & 26.12 & 13.47 & 0.72 \\
\hline $\mathrm{Fe}_{2} \mathrm{O}_{3}$ & 2.53 & 3.46 & 3.01 & 7.25 & 1.15 & 0.05 \\
\hline $\mathrm{MgO}$ & 2.71 & 3.56 & 29.1 & 2.49 & 2.51 & 0.40 \\
\hline $\mathrm{SO}_{3}$ & 2.38 & 2.1 & 2.38 & 0.8 & 1.12 & 0.43 \\
\hline
\end{tabular}

Table 3 The mixture proportions of the concretes and the sorts of the adding aggregates.

\begin{tabular}{|c|c|c|c|c|c|c|c|}
\hline Sample No & $\mathrm{C} 30$ & $\mathrm{C} 35$ & $\mathrm{C} 40$ & $\mathrm{C} 50$ & $\mathrm{C} 60$ & $\mathrm{C} 70$ & $\mathrm{C} 80$ \\
\hline Aggregate sort & LS-1 & GS-1 & GS-1 & LS-1 & LS-1 & LS-1 & GS-1 \\
\hline Sand sort & DS & DS & DS & YS & YS & YS & DS \\
\hline Cement grade & P.O 42.5 & P.S 32.5 & P.O 42.5 & P.O 42.5 & P.O 42.5 & P.O 52.5 & P.O 52.5 \\
\hline Cement $\mathrm{kg} / \mathrm{m}^{3}$ & 286 & 344 & 316 & 386 & 326 & 391 & 411 \\
\hline Fly ash $\mathrm{kg} / \mathrm{m}^{3}$ & 90 & 148 & - & 90 & - & - & - \\
\hline GGBS $\mathrm{kg} / \mathrm{m}^{3}$ & - & - & 150 & - & 160 & 110 & 90 \\
\hline Silica Fume $\mathrm{kg} / \mathrm{m}^{3}$ & - & - & - & - & - & 44 & 44 \\
\hline Coarse aggregate $\mathrm{kg} / \mathrm{m}^{3}$ & 1,113 & 1,141 & 1,069 & 1,159 & 1,159 & 1,088 & 1,096 \\
\hline Sand $\mathrm{kg} / \mathrm{m}^{3}$ & 724 & 614 & 713 & 624 & 624 & 612 & 616 \\
\hline $\mathrm{W} / \mathrm{B}$ & 0.45 & 0.33 & 0.36 & 0.33 & 0.33 & 0.28 & 0.27 \\
\hline Sand ratio $\%$ & 39 & 35 & 40 & 35 & 35 & 36 & 36 \\
\hline Superplasticizer \% & 0.9 & 1 & 1.2 & 0.8 & 0.8 & 1.2 & 1.2 \\
\hline Slump mm & 165 & 260 & 225 & 190 & 190 & 225 & 235 \\
\hline Adding aggregate sort & LS-1 & DS-1 & LS-2 & LS-1 & LS-1 & LS-1 & LS-1 \\
\hline
\end{tabular}

scattering-filling aggregate process by adding $20 \%$ volume ratio of coarse aggregates to substitute the conventional concretes mixtures, the 7 and 28 days strengths of those concretes with different content of adding coarse aggregate contents are illustrated in Fig. 2.

It can be found that the strengths of all those concretes with different mix proportions increase obviously with the $20 \%$ (the volume ratio of scattering concrete in the finished concrete) adding aggregate ratio only different in the extent. The increasing ratio can be as high as $25 \%$. It is easy to find that concretes with $50-100 \mathrm{MPa}$ have been prepared with only $362-440 \mathrm{~kg} / \mathrm{m}^{3}$ of cement or binder when $20 \%$ coarse aggregate is scattered to substitute the original concrete mixtures through some simple calculation, this can be never achieved with the conventional concrete placing process. The scattering-filling coarse aggregate can prepare concrete with very high coarse aggregate, although the "pre-placed aggregate" concrete process (Neville 1981) can prepare concrete with as low cement dosage as this process, but it can only prepare low or middle strength concrete. The scattering-filling aggregate method can produce consolidated concrete with less cement but higher strength and performances at the same time, the decrease on cement dosage not

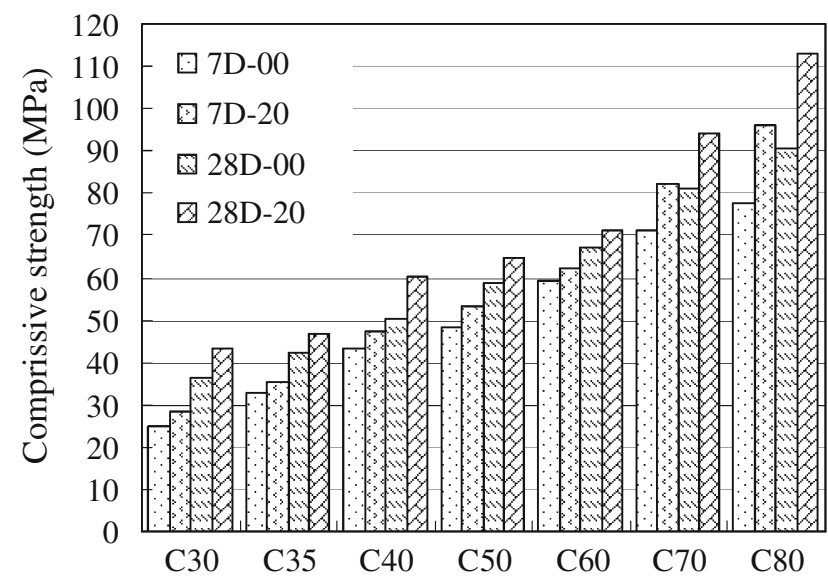

Fig. 2 The strengths of concretes with different adding aggregate ratios. 
only give the concrete good cost competitive but also good environmental harmonization. The optimal volume percentage of the scattering aggregate in the concrete depends on the void ratio of coarse aggregate in the original concrete and the flowability of the concrete, the looser the aggregated packs and the more flowable, the more the scattering aggregate can be added, around 5-12\% of aggregate can be scattered in the pavement concrete. The scattering-filling aggregate process can be potentially apply in nearly all kind of conventional plastic and flowing concrete, is especially suitable to be used in pumped concrete for its high mortar content.

\subsection{The Shrinkage of the Coarse Aggregate Interlocking Concrete}

The shrinkage crack of concrete sometime results in damage of concrete structures, increasing of the aggregate can reduce the crack of concrete. The relation between the concrete shrinkage and the content of the aggregate in the concrete can be described as (Mindess et al. 2003):

$$
S_{\mathrm{c}}=S_{\mathrm{p}}(1-\alpha)^{n}
$$

Where $S_{\mathrm{c}}$ and $S_{\mathrm{p}}$ is the shrinkages of the concrete and the paste respectively, $\alpha$ is the volume fraction of the aggregate in the concrete and $n$ is a constant which varies between 1.2 and 1.7 depending on the elasticity of the concrete. The shrinkage curves of the concretes with different scatteringfilling aggregate replacement volume fractions are illustrated in Fig. 3.

Figure 3 indicates that with the increase of the replacement volume fraction of the scattering-filling aggregate, the shrinkage of the concrete decreases significantly. With increasing of the volume fraction of the extra coarse aggregate is added to the concrete, the shrinkage of the concrete decreases markedly. The aggregate scattering-filling process is a very effective approach to reduce the shrinkage

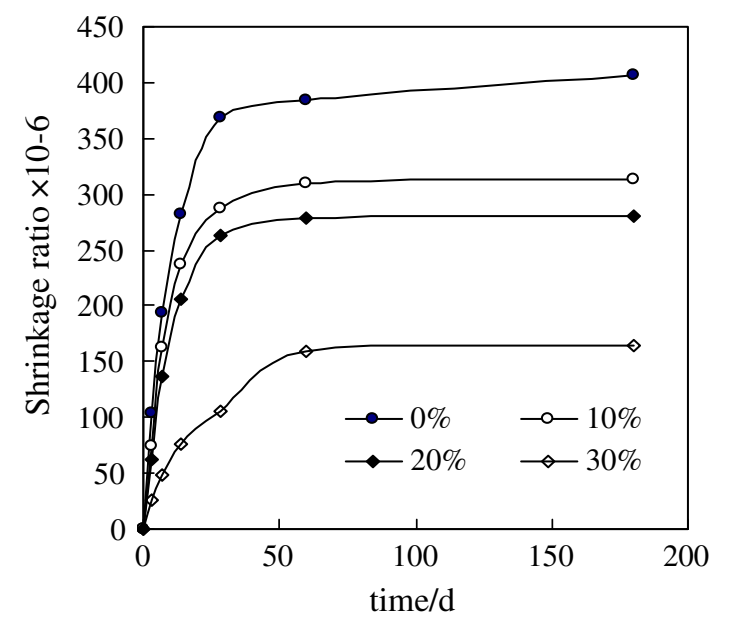

Fig. 3 The shrinkage of the concretes with different adding aggregate ratios.

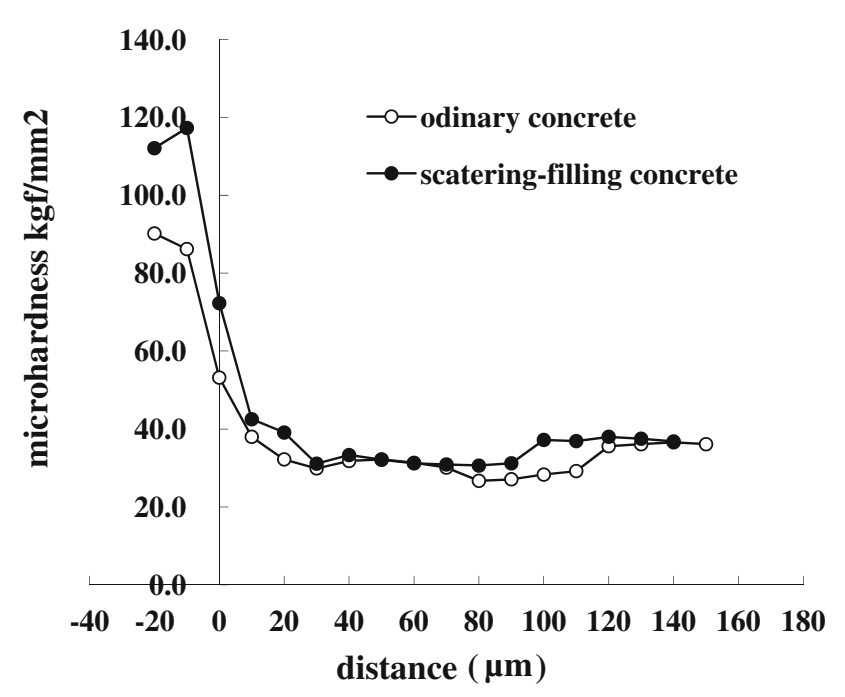

Fig. 4 The micro-hardness of the ITZ.

of the high strength concrete, which is highly desired by engineers (Mindess et al. 2003).

\subsection{The Micro-Hardness Distribution of the Aggregate Paste ITZ}

Figure 4 illustrated the micro-hardness distribution of the ITZ in ordinary concrete and scattering-filling concrete, the rigid origin of $X$ axis is the edge of the aggregate can be found in the microscopy. It is easy to see that the microhardness of the scatting-filling aggregate is much higher than that of the ordinary concrete. Generally, the ITZ has the lower hardness than aggregate and cement paste (Ping and Beaudoin 1992). If the edge of ITZ is where the microhardness begin to increase, the width of the ITZ in the ordinary concrete is around $110 \mu \mathrm{m}$ but the ITZ in the scattering-filling aggregate concrete is $90 \mu \mathrm{m}$. This test result also can be explained with the water absorption of the air dry coarse adding aggregate which enhance the microstructure of the ITZ.

\subsection{The Mechanism of the Coarse Aggregate Interlocking Concrete}

There are many kinds of process to produce concrete with high coarse aggregate volume fraction, e.g. pre-placing aggregate concrete, Roller-compacted concrete, and some concrete with low cement content (Neville 1981; Ping and Beaudoin 1992; Nadeau 2003). Unfortunately, those processes typically can only prepare low or middle strength concrete (Neville 1981), the result of Fig. 2 indicated that concrete with a strength degrade ranging from $\mathrm{C} 30$ to $\mathrm{C} 80 \mathrm{MPa}$ can be prepared with this scattering-filling coarse aggregate process although this kind of aggregate interlocking concrete has very low cement dosage. The mechanism of the concrete process can be explained with following three aspects.

First of all, the coarse aggregate volume fraction increases dramatically in this type of concrete when more than $20 \%$ of coarse aggregate is scattered in the mixture, the coarse aggregates can interlock with each other, the friction forces 
among the aggregate contribute to the strength enhance in a certain extent. The second, the coarse aggregate distributes more evenly in this kind of concrete than the concrete prepared with conventional process. With the vibration, the segregation of the coarse aggregate toward the bottom of the form and the of the cement paste toward the top may result in the conventional concrete (Mindess et al. 2003), the surface of the concrete will be very weak, but when scattingfilling process is applied, the coarse aggregate will fill evenly at the top of the form. The third, the addition of extra amount of air dry coarse aggregates acts as somewhat water reducer, not only reduces the $\mathrm{W} / \mathrm{C}$ of the paste close to the aggregate and make the paste stronger so the ITZ of the concrete is enhanced. With the volume fraction of the aggregate increasing, as a composite material, the concrete will become stronger and stiffer.

\section{Conclusions}

This article relates to a new type of aggregate interlocking concrete placed with scattering-filling aggregate process, which is a new process developed by the first author. An experimental study on the strength and the dry shrinkage of the aggregate interlocking concrete and the microstructure of the paste aggregate ITZ is presented. The results give rise to the following conclusions:

1. $\mathrm{C} 30-\mathrm{C} 80$ concrete with higher strength is prepared but lower cement dosage is prepared with scattering-filling aggregate method.

2. The dry shrinkage of the aggregate interlocking concrete decrease with the increase of volume ratio of the extra adding aggregate.

3. The surfaces and the pores of the adding aggregates absorb water from cement paste around them, so much tighter and narrower ITZ is formed in the scatteringfilling aggregate concrete.

4. The interlocking, more even distribution of the coarse aggregates and the water absorption of the extra adding aggregate contributed to the strength and performances improvement of this new type of concrete.

\section{Acknowledgments}

The author acknowledges the funding support of Hubei Highway Bureau, the funding support of Guangdong Transportation Ministry 2011-03-057 and 2012-03-006.

\section{Open Access}

This article is distributed under the terms of the Creative Commons Attribution License which permits any use, distribution, and reproduction in any medium, provided the original author(s) and the source are credited.

\section{References}

Alexanderson, J. (1971). The influence of the properties of cement and aggregates on the consistency of concrete. Proceedings RILEM Seminar, 23(2), 12-22.

Beshr, H., Almusallam, A. A., \& Maslehuddin, M. (2003). Effect of coarse aggregate quality on the mechanical properties of high strength concrete. Construction and Building Materials, 17(2), 97-103.

Beste, U., \& Jacobson, S. (2003). Micro scale hardness distribution of rock types related to rock drill wear. Wear, 254(5), $1147-1154$.

Counto, U. J. (1964). The effect of elastic modulus of the aggregate on the elastic modulus, creep and creep recovery of concrete. Magazine of Concrete Research, 16(2), 129.

Hirsch, T. J. (1962). Modulus of elasticity of concrete affected by elastic module of cement paste matrix and aggregate. ACI Materials Journal, 59(3), 427-451.

Mehta, P. K. (1999). Concrete technology for sustainable development. Concrete International, 21(11), 47-53.

Mehta, P. K., \& Monteiro, P. J. M. (1993). Concrete: Microstructure, properties, and materials. New York, NY: McGraw-Hill.

Mindess, S., Young, J. F., \& David, D. (2003). Concrete (2nd ed.). New Jersey, NJ: Pearson Education Inc.

Mizuguchi, H. (1998). A review of environmentally friendly concrete. Concrete International, 36(1), 9-12.

Nadeau, J. C. (2003). A multiscale model for effective module of concrete incorporating ITZ water-cement ratio gradients, aggregate size distributions, and entrapped voids. Cement and Concrete Research, 33(1), 103-113.

Neville, F. M. (1981). Properties of concrete. London, UK: Pitman publishing limited.

Nilsen, A. U., \& Monteiro, P. J. M. (1993). Concrete: A three phase material. Cement and Concrete Research, 23(2), 147-151.

Özturan, T., \& Çeçen, C. (1997). Effect of coarse aggregate type on mechanical properties of concretes with different strengths. Cement and Concrete Research, 27(2), 165-170.

Ping, X., \& Beaudoin, J. J. (1992). Effects of transition zone microstructure on bond strength of aggregate portland cement paste interfaces. Cement and Concrete Research, 22(1), 23-26.

Van Oss, H. G., \& Padovani, A. C. (2003). Cement manufacture and the environment, Part II: environmental challenges and opportunities. Journal of Industrial Ecology, 7(1), 93-126.

Shen, W., Dong, R., Li, J., et al. (2010a). A study on the coarse aggregate interlocking concrete. Construction and building material, 24(11), 2312-2316.

Shen W, Cai Z, Zhou M. High strength coarse aggregate interlocking concrete: preparation and properties, 8th International symposium on Utilization of High-Strength and High Performance Concrete (fib), 2008, Tokyo, Japan, 188-192.

Shen, W., Zhang, T., Zhou, M., et al. (2010b). Investigation on the scattering-filling coarse aggregate self-consolidating concrete. Materials and Structures, 43(10), 1343-1350.

Stock, A. F., Hannant, D. J., \& Williams, R. I. T. (1979). The effect of aggregate concentration upon the strength and modulus of elasticity of concrete. Magazine of Concrete Research, 31(2), 225-234. 